BACKGROUND: Platelet-activating factor (PAF) seems to be implicated in systemic lupus erythematosus (SLE) patients with associated renal diseases.Aims: In this study, we ensured the role of PAF in SLE patients without renal complications.

Methods: Blood PAF and acetylhydrolase activity, plasma soluble phospholipase $A_{2}$, and the presence of antibodies against PAF were investigated in 17 SLE patients without active nephritis and in 17 healthy controls.

Results: Blood PAF levels were not different $(p=$ $0.45)$ between SLE patients $(6.7 \pm 2.8 \mathrm{pg} / \mathrm{ml})$ and healthy subjects $(9.6 \pm 3.1 \mathrm{pg} / \mathrm{ml})$. Plasma acetylhydrolase activity (the PAF-degrading enzyme) was significantly $(p=0.03)$ elevated in SLE patients $(57.8 \pm 6.4 \mathrm{nmol} / \mathrm{min} / \mathrm{ml})$ as compared with controls $(37.9 \pm 2.6 \mathrm{nmol} / \mathrm{min} / \mathrm{ml})$. Plasma soluble phospholipase $\bar{A}_{2}$ (the key enzyme for PAF formation) was not different $(p=0.6)$ between SLE patients $(59.1 \pm 5.1 \mathrm{U} /$ $\mathrm{ml}$ ) and controls $(54.7 \pm 2.4 \mathrm{U} / \mathrm{ml})$. Antibodies against PAF were detected only in 3/17 SLE patients. Flow cytometry analysis did not highlight PAF receptors on circulating leukocytes of SLE patients.

Conclusion: This clinical study highlights no evidence for a putative important role of PAF in SLE patients without active nephritis.

Key words: Acetylhydrolase activity, Platelet-activating factor, Soluble phospholipase $A_{2}$, Systemic lupus erythematosus

\section{No evidence for a putative involvement of platelet-activating factor in systemic lupus erythematosus without active nephritis}

Yves Denizot ${ }^{1, C A}$, Eric Liozon ${ }^{2}$, Laurence Guglielmi ${ }^{1}$, Kim Ly², Pascale Soria ${ }^{2}$, Véronique Loustaud ${ }^{2}$, Elisabeth Vidal $^{2}$ and Marie Odile Jauberteau ${ }^{1}$

${ }^{1}$ UMR CNRS 6101, Laboratoire d'Immunologie, Faculté de Médecine, 2 rue Dr Marcland, 87025 Limoges, France; ${ }^{2}$ Service de Médecine Interne, $\mathrm{CHU}$ Dupuytren, Limoges France

\footnotetext{
${ }^{\mathrm{CA}}$ Corresponding author

Tel: +33555435896

Fax: +33555435897

E-mail: yves.denizot@unilim.fr
}

\section{Introduction}

Platelet-activating factor (PAF) is a phospholipid compound produced by stimulated inflammatory cells such as monocytes, neutrophils, and eosinophils. ${ }^{1}$ PAF is not stored in cells, but is derived from a membrane precursor, 1-alkyl-2-acyl-glycero-3-phosphocholine. The action of a phospholipase $\mathrm{A}_{2^{-}}$ dependent process generates the lyso-PAF, and the subsequent acetylation of the lyso compound results in the PAF molecule. ${ }^{1}$ PAF concentrations are regulated by an acetylhydrolase activity (AHA) found both in plasma and serum. ${ }^{2,3}$ PAF acts through protein-Gcoupled PAF receptors (PAF-R) present on the membrane of responsive cells. ${ }^{4}$ PAF sparks a wide range of inflammatory actions on various cells and organs including the kidneys. ${ }^{5,6}$ Thus, elevated blood PAF levels are reported in patients with glomerulonephritis $^{7}$ and idiopathic immunoglobulin (Ig)A nephropathy. ${ }^{8}$

Studies suggest that PAF may play a role in systemic lupus erythematosus (SLE) patients. Thus, PAF enhances immunoglobulin production by $B$ lymphocytes. ${ }^{9,10}$ Elevated plasma PAF levels are reported during the most active phases of the disease, ${ }^{11}$ and monocytes from active SLE patients produce higher levels of PAF compared with inactive patients and controls. ${ }^{12}$ AHA levels are also affected in human SLE. Thus, studies report either reduced or elevated AHA levels in SLE patients as compared with healthy controls. ${ }^{11,13}$ SLE is often characterised by the development of immune complex glomerulonephritis; lupus nephritis being a leading cause of morbidity and mortality in SLE. ${ }^{14}$ Since the PAF/AHA couple is deregulated during renal diseases, ${ }^{5-8}$ it is difficult to state whether PAF may be defined as a pathogenic mediator in SLE or is only the reflection of the presence of associated diseases, especially renal ones. Moreover, if abnormal serum lipid profiles are common in patients with active SLE, they are absent in SLE patients without renal diseases. ${ }^{15}$ In this study, we investigated blood PAF levels and plasma AHA in SLE patients without active nephritis. We also assessed their plasma soluble phospholipase $\mathrm{A}_{2}\left(\mathrm{sPLA}_{2}\right)$ levels, the presence of antibodies against PAF and the presence of PAF-R on their peripheral blood cells. 


\section{Subjects and methods}

\section{Subjects}

Blood samples were obtained following the Helsinki recommendations. PAF from whole blood and plasma AHA levels were investigated in 17 SLE patients (16 females, one male), aged from 20 to 80 years (mean \pm SEM, 39.2 \pm 4.1 years), without renal involvement (no proteinuria and haematuria), who fulfilled the criteria of the American Rheumatism Association for the diagnosis of SLE, ${ }^{14}$ including four patients with incomplete SLE. ${ }^{16}$ At the time of the study, seven patients had inactive SLE (Systemic Lupus Erythematosus Disease Activity Index (SLEDAI) score $\leq 3$ ) and 10 had active SLE (SLEDAI score > 3) ${ }^{17}$ Clinical data of SLE patients are reported in Table 1. Seventeen healthy volunteers (16 females, one male), aged from 26 to 90 years (mean \pm SEM, $44.0 \pm 4.7$ years), were investigated as controls.

\section{PAF and AHA assay}

Two millilitres of blood were ethanol extracted, purified using thin-layer chromatography, and assayed for PAF activity by aggregation of washed rabbit platelets. ${ }^{8,18}$ AHA was assessed by investigating the degradation of ${ }^{3} \mathrm{H}$-labeled-PAF. ${ }^{18}$

\section{Analysis of PAF-R}

Two hundred microlitres of blood were incubated with PAF-R mouse monoclonal antibodies (Spi Bio, Massy, France) for $30 \mathrm{~min}$. After washing, cells were incubated with fluorescein isothiocyanate (FITC)labelled goat-anti mouse antibodies (Dakopatts, Glostrup, Denmark) for $30 \mathrm{~min}$. After washing, cells were labelled with phycoerythrin (PE)-labelled antiCD3, anti-CD19 or anti-CD13 antibodies (Immuno- tech, Marseille, France) to stain lymphocytic, monocytic and granulocytic populations. The cell suspension was then submitted to flow cytometric analysis (XL II, Coulter, Margency, France). ${ }^{19}$

\section{Enzyme-linked immunosorbent assay for antibodies to PAF}

This enzyme-linked immunosorbent assay (ELISA) was performed on plasma samples as previously described by Tektonidou et al. ${ }^{20}$

\section{ELISA for $\mathrm{PPLA}_{2}$}

The SPLA $_{2}$ plasma levels were assessed by ELISA according to the manufacturer's recommendations (R\&D Systems Europe, Ltd, Oxon, UK). Results were expressed as units per millilitre.

\section{Statistical analysis}

Differences between groups were assessed using the Mann-Whitney U-test. $p<0.05$ was considered significant.

\section{Results \\ PAF levels in SLE patients}

As shown in Fig. 1A, no significant difference $(p=$ 0.45, Mann-Whitney U-test) was documented for blood PAF levels between SLE patients $(6.7 \pm 2.8 \mathrm{pg} /$ $\mathrm{ml}, n=17)$ and a sex-matched and aged-matched control group of healthy individuals $(9.6 \pm 3.1 \mathrm{pg} / \mathrm{ml}$, $n=17)$. Similarly, no difference was noticed between blood PAF levels of SLE patients with active or inactive disease (data not shown). The plateletaggregating activity recovered from blood was indis-

Table 1. Clinical and biological data of SLE patients at the time of the investigation

\begin{tabular}{lccll}
\hline Patient number & Sex/age (years) & SLEDAl score* & \multicolumn{1}{c}{ Data $^{\dagger}$} & \\
\hline 1 & Female/20 & 2 & $1,2,5,6$ & Medication \\
2 & Female/71 & 1 & $1,4,6$ & Hydroxychloroquine; acetyl salicylic acid \\
3 & Male/30 & 5 & $1,2,6$ & Hydroxychloroquine; azathioprine \\
4 & Female/33 & 5 & $1,2,6,7$ & Prednisolone; hydroxychloroquine \\
5 & Female/23 & 4 & $1,4,5,6$ & Prednisolone; hydroxychloroquine \\
6 & Female/35 & 2 & $1,2,6$ & Hydroxychloroquine \\
7 & Female/25 & 1 & $1,2,6$ & None \\
8 & Female/69 & 11 & $1,2,3,4,5,6,7$ & Prednisolone \\
9 & Female/32 & 3 & $3,4,5,6,7$ & Hydroxychloroquine \\
10 & Female/42 & 10 & 4,6 & None \\
11 & Female/80 & 5 & 1,5 & Hydroxychloroquine; diclofenac \\
12 & Female/37 & 4 & $2,3,4,5,6,7$ & None \\
13 & Female/28 & 0 & $4,5,6$ & Prednisolone \\
14 & Female/55 & 4 & $1,2,4,5,6,7$ & Hydroxychloroquine; prednisolone \\
15 & Female/49 & 10 & $1,6,7$ & Hydroxychloroquine \\
16 & Female/51 & 12 & $1,2,4,5,6,7$ & Prednisolone; cyclophosphamide \\
17 & Female/32 & 2 & $1,4,5,6,7$ & Hydroxychloroquine; acetyl salicylic acid \\
\hline
\end{tabular}

*SLEDAl, Systemic lupus erythematosus disease activity index.

${ }^{\dagger} 1$, arthralgia or non-erosive polyarthritis; 2 , skin eruption; 3 , clinical manifestations of anti-phospholipid syndrome; 4, haematological disorders; 5, positive anti-DNA antibodies; 6, positive anti-nuclear antibodies; 7, positive anti-phospholipid antibodies. 

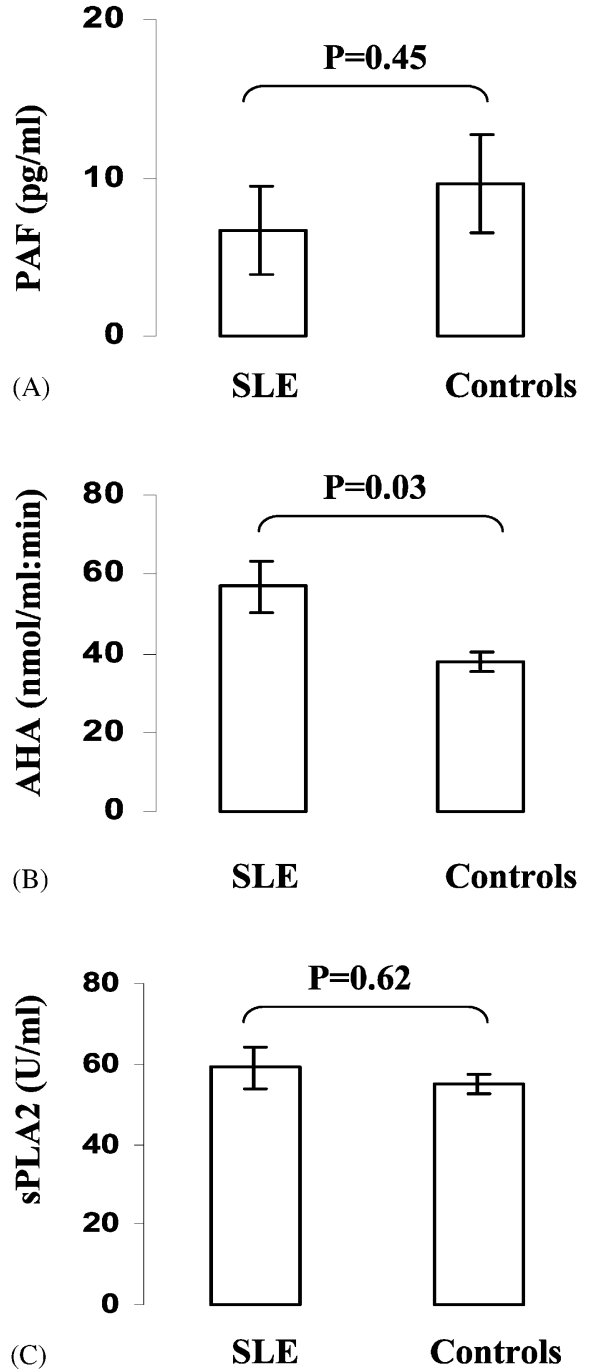

FIG. 1. (A) Blood PAF, (B) plasma $A H A$ and (C) $s P L A_{2}$ levels in SLE patients without active nephritis and in healthy controls. Differences between groups were assessed using the MannWhitney U-test.

tinguishable from synthetic PAF by the following physicochemical and biological criteria. First, it induced in a dose-dependent manner the aggregation of washed rabbit platelets that were refractory to arachidonic acid and ADP-mediated pathways; second, the platelet aggregating activity was totally inhibited by $0.1 \mathrm{mM}$ of $\mathrm{BN} 52021$, a specific PAF receptor antagonist; and third, the aggregating activity exhibited, on thin-layer chromatography, a retention time similar to that of synthetic PAF (data not shown).

\section{AHA level in SLE patients}

As shown in Fig. 1B, AHA (the PAF catabolic enzyme) levels were significantly $(p=0.03)$ elevated in SLE patients $(56.8 \pm 6.4 \mathrm{nmol} / \mathrm{min} / \mathrm{ml})$ as compared with in healthy controls $(37.9 \pm 2.6 \mathrm{nmol} / \mathrm{min} / \mathrm{ml})$. No difference was noticed between plasma AHA levels of SLE patients with active or inactive disease (data not shown). No correlation between PAF and AHA levels was observed in SLE patients $(r=0.4, p=0.1)$.

\section{sPLA $A_{2}$ levels in SLE patients}

As shown in Fig. 1C, sPLA 2 (the key enzyme for the generation of the PAF precursor, lyso-PAF) levels were not different $(p=0.62)$ between SLE patients $(59.1 \pm 5.1 \mathrm{U} / \mathrm{ml})$ and healthy controls $(54.7 \pm 2.4 \mathrm{U} /$ $\mathrm{ml})$. No difference was found between sPLA 2 levels of SLE patients with active or inactive disease, and no correlation between $\mathrm{SPLA}_{2}$ and PAF or AHA levels were observed (data not shown).

\section{Anti-PAF antibodies in SLE patients}

As shown in Fig. 2, antibodies against PAF were detected in 3/17 (17.6\%) patients (two with an active disease and one with a non-active disease). The presence of antibodies against PAF was not correlated with the presence of an anti-phospholipid syndrome (data not shown).

\section{PAF-R on blood cells of SLE patients}

Results of flow cytometry experiments did not highlight the presence of PAF-R on the membrane of $\mathrm{T}$ and $\mathrm{B}$ lymphocytes, monocytes and granulocytes of SLE patients (data not shown).

\section{Discussion}

Studies have reported a role of PAF in SLE patients with associated renal involvement. Thus, data reported alterations of PAF and AHA levels, and the presence of antibodies against PAF in SLE patients. ${ }^{11,13,20,21}$ Strengthening clinical results, PAF-R blockade reduced proteinuria, prevented chronic glomerular histologic changes and improved survival in lupus autoimmune mice (lpr and NZBxW

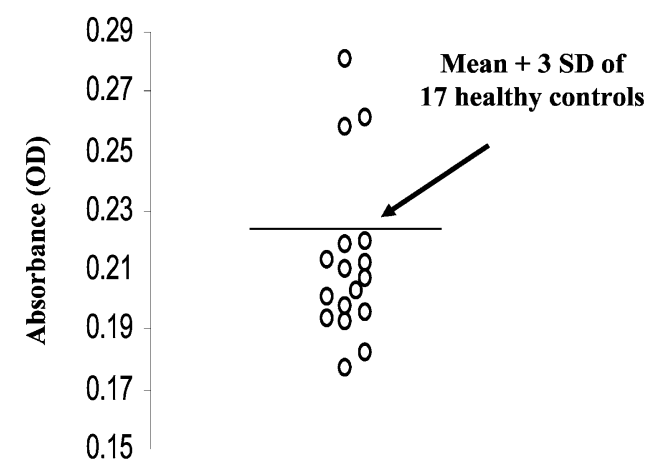

FIG. 2. Antibodies against PAF in SLE patients without active nephritis. Seventeen SLE patients were evaluated in anti-PAF assays. The upper limit of normal was set at three standard deviations above the mean of the absorbance values of 17 healthy controls. 
mice). ${ }^{22,23}$ In this study, we investigated whether PAF might be involved in SLE patients without active nephritis.

PAF is routinely measured by a variety of bioassays, including the platelet-aggregation assay. PAF levels can also be determined with a radioimmunoassay (RIA). A good correlation for the measurement of PAF has been reported between results with the plateletaggregation assay and the RIA. ${ }^{24}$ Although the RIA was slightly more sensitive and reproducible than the platelet-aggregation assay, the bioassay has the advantage of being rapid and inexpensive. Although $\mathrm{PAF}$ is viewed as a single molecular entity, it is composed of a C-16:0, C-18:0 and C-18:1 alkyl chain in the sn-1 position. ${ }^{25}$ The length of the 1-0-alkyl chain has an important effect on the potency of PAF biological effects. For example, C-18:1 PAF is 100-fold more potent in decreasing coronary flow than C-18:0 PAF, while C-16:0 PAF is far more potent than C-18:0 PAF to aggregate platelets. The bioassay thus reveals the total biological aggregating activity of the bloodderived PAF. In contrast, the RIA has a different sensitivity for C-16 and C-18 PAF. ${ }^{26}$ In this study, we have used the platelet-aggregation assay to ensure blood PAF concentrations of SLE patients.

Results of this short clinical study indicate that blood PAF levels are not increased in SLE patients without active nephritis. We may speculate that the elevated PAF levels in SLE patients reported by Tetta et $a l .{ }^{11}$ might be linked to their associated renal diseases rather than to SLE itself. Strengthening this hypothesis, higher blood PAF levels are reported in non-SLE patients with glomerulonephritis ${ }^{7}$ and idiopathic IgA nephropathy. ${ }^{8}$ We confirm that AHA levels are elevated in SLE patients as compared with in healthy individuals. ${ }^{13}$ However, the AHA increase is modest and sheds little light on its role in SLE patients since this enzyme is also elevated in several other non-immune diseases such as asthma, hepatic and rheumatic diseases, hypertension, diabetes, sepsis and stroke. ${ }^{2}$ Whatever the origin of these elevated AHA levels, they do not argue in favour of an important role of PAF in SLE patients without active nephritis. Phospholipase $\mathrm{A}_{2}$ is the key enzyme for the synthesis of the PAF precursor, lyso-PAF. ${ }^{1}$ Plasma $\mathrm{SPLA}_{2}$ levels are not changed in SLE patients without active nephritis. This result is, for another time, not in favour of a role of PAF in these patients. Similarly to previous reports, ${ }^{20,21}$ anti-PAF antibodies can be detected in SLE patients. Whatever the function of anti-PAF antibodies (if any), their low frequency (3/ 17 patients) does not argue in favour of an important role of PAF in SLE patients without active nephritis, and brings some doubts concerning the usefulness of their detection in clinical practice. Finally, PAF acts through PAF-R present on the membrane of responsive cells. PAF is known to enhance, in vitro, the number of its own receptors on blood cell types such as monocytes and lymphocytes. ${ }^{27,28}$ Speculating that if PAF acts during SLE it might have a similar effect, we thus investigated the presence of membrane PAF$\mathrm{R}$ on circulating blood cells of SLE patients. Our results indicate that PAF-R is not detected on lymphocytes, monocytes and granulocytes of SLE patients without active nephritis.

In conclusion, blood PAF levels are not elevated in SLE patients without active nephritis. While their plasma AHA levels are modestly increased, their plasma $\mathrm{PLA}_{2}$ levels are stable and anti-PAF antibodies are not common. Finally, no PAF-R is found on their circulating leukocytes. Taken together, results of this clinical study highlight no evidence for a potential important role of PAF in SLE patients without active nephritis. However, it must be pointed out that patients' medications might have affected processes leading to PAF formation and/or degradation. Further experiments investigating the role of these therapeutical treatments on PAF, SPLA2 and AHA levels on steady-state conditions could be of interest to clarify this point.

ACKNOWLEDGEMENTS. This work was supported by grants from the 'Association Recherche et Entraide des Maladies Lupiques - Region Limousin'.

\section{References}

1. Denizot Y. Platelet-activating factor: biosynthesis, biodegradation, actions. In: von Bruchhausen F, Walter U, eds. Handbook of Experimental Pharmacology: Platelets and their Factors, Berlin: Springer, 1997: 483-506.

2. Stafforini DM, Prescott SM, Zimmerman GA, McIntyre TM. Mammalian platelet-activating factor acetylhydrolases. Biochim Biophys Acta 1996; 1301: $161-173$

3. Stafforini DM, Satoh KS, Atkinson DL, et al. Platelet-activating factor acetylhydrolase deficiency. A missense mutation near the active site of an anti-inflammatory phospholipase. J Clin Invest 1996; 97: 2784-2791.

4. Izumi T, Shimizu T. Platelet-activating factor receptor: gene expression and signal transduction. Biochim Biophys Acta 1995; 1259: 317-333.

5. Imaizumi TA, Stafforini DM, Yamada Y, McIntyre T, Prescott SM, Zimmerman GA. Platelet-activating factor: a mediator for clinicians. $J$ Intern Med 1995; 238: 5-20.

6. Lopez-Novoa J. Potential role of platelet-activating factor in acute renal failure. Kidney Int 1999; 55: 1672-1682.

7. Iatrou C, Moustakas G, Antonopoulou S, Demopoulos CA, Ziroyiannis P. Platelet-activating factor levels and PAF acetylhydrolase activities in patients with primary glomerulonephritis. Nephron 1996; 72: 611-616.

8. Denizot Y, Aupetit C, Bridoux F, Alphonse JC, Cogné M, Aldigier JC. Deregulated platelet-activating factor levels and acetylhydrolase activity in patients with idiopathic IgA nephropathy. Nephrol Dial Transplant 2000; 15: 1344-1347.

9. Smith CS, Shearer WT. Activation of NF- $\mathrm{\kappa B}$ and immunoglobulin expression in a human B cell line. Cell Immunol 1994; 155: 292-303.

10. Mazer BD, Sawami H, Franklin R, Gelfand EW. B-cell activation and regulation of immunoglobulin synthesis by platelet-activating factor. Neth J Med 1991; 39: 244-253.

11. Tetta C, Bussolino F, Modena V, Montrucchio G, Segoloni G, Pescarmona $G$, Camussi $G$. Release of platelet-activating factor in systemic lupus erythematosus. Int Arch Allergy Appl Immunol 1990; 91: $244-$ 256.

12. Bussolati B, Rollino C, Mariano F, Quarello F, Camussi G. IL-10 stimulates production of platelet-activating factor by monocytes of patients with active systemic lupus erythematosus (SLE). Clin Exp Immunol 2000; 122: 471-476.

13. Matsuzaki M, Ishiguro Y, Tetsumoto T, Tsukada Y, Kayahara H, Tadasa K. PAF acetylhydrolase activities in human systemic lupus erythematosus and lupus-prone mice. Clin Chim Acta 1992; 210: 139-144.

14. Tan EM, Cohen AS, Fries JF, et al. The revised criteria for the classification of systemic lupus erythematosus. Arthritis Rheum 1982; 25: $1271-1277$. 
15. Vila LM, Mayor AM, Valentin AH, Garcia-Soberal M, Vila S. Clinical outcome and predictors of disease evolution in patients with incomplete lupus erythematosus. Lupus 2000; 9: 110-115.

16. Leong KH, Koh ET, Feng PH, Boey ML. Lipid profiles in patients with systemic lupus erythematosus. J Rheumatol 1994; 21: $1264-1267$.

17. Bombardier C, Gladman DD, Urowitz MB, Caron D, Chang $\mathrm{CH}$ Derivation of the SLEDAI. A disease activity index for lupus patients The committee on prognosis studies in SLE. Arthritis Rhem 1992; 35 630-640.

18. Denizot Y, Desplat V, Drouet M, Bertin F, Melloni B. Is there a role of platelet-activating factor in human lung cancer? Lung Cancer 2001; 33 $195-202$.

19. Desplat V, Besse A, Faucher JL, Praloran V, Denizot Y. Expression of platelet-activating factor receptor transcript- 1 but not transcript-2 by human bone marrow cells. Stem Cells 1999; 17: 121-124.

20. Tektonidou MG, Petrovas CA, Ioannidis JP, Vlachoyiannopoulos PG Moutsopoulos HM. Clinical importance of antibodies against plateletactivating factor in antiphospholipid syndrome manifestations. Eur J Clin Invest 2000; 30: 646-652

21. Barquinero J, Ordi-Ros J, Selva A, Perez-Peman P, Vilardell M, Khamashta M. Antibodies against platelet-activating factor in patients with antiphospholipid antibodies. Lupus 1994; 3: 55-58

22. Baldi E, Emancipator SN, Hassan MO, Dunn MJ. Platelet activating factor receptor blockade ameliorates murine systemic lupus erythematosus Kidney Int 1990; 38: 1030-1038.
23. Morigi M, Macconi D, Riccardi E, Boccardo P, Zilio P, Bertani T, Remuzzi G. Platelet-activating factor receptor blocking reduces proteinuria and improves survival in lupus autoimmune mice. J Pharmacol Exp Ther 1991; 258: 601-606.

24. Ammit AJ, O'Neill C. Comparison of a radioimmunoassay and bioassay for embryo-derived platelet-activating factor. Human Reprod 1991; 6: $872-878$.

25. McManus LM, Woodard DS, Deavers SI, Pinkard RN. PAF molecular heterogeneity: pathobiological implications. Lab Invest 1993; 69: 639650 .

26. Baldo BA, Smal MA, McCaskill AC. A specific, sensitive and highcapacity immunoassay for PAF. Lipids 1991; 26: 1136-1139.

27. Shirasaki H, Adcock IM, Kwon OJ, Nishikawa M, Mak JC, Barnes PJ. Agonist-induced up-regulation of platelet-activating factor receptor messenger RNA in human monocytes. Eur J Pharmacol 1994; 268: $263-266$.

28. Nguer CM, Treton D, Rola-Pleszczynski M, Mishal Z, Thomas Y, Galanaud P, Richard Y. Regulation of platelet-activating factor receptor expression in human B cells and B cell lines. Lipids 1996; 31: 10511058.

Received 16 December 2002

Accepted 29 January 2003 


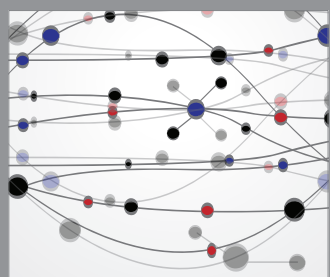

The Scientific World Journal
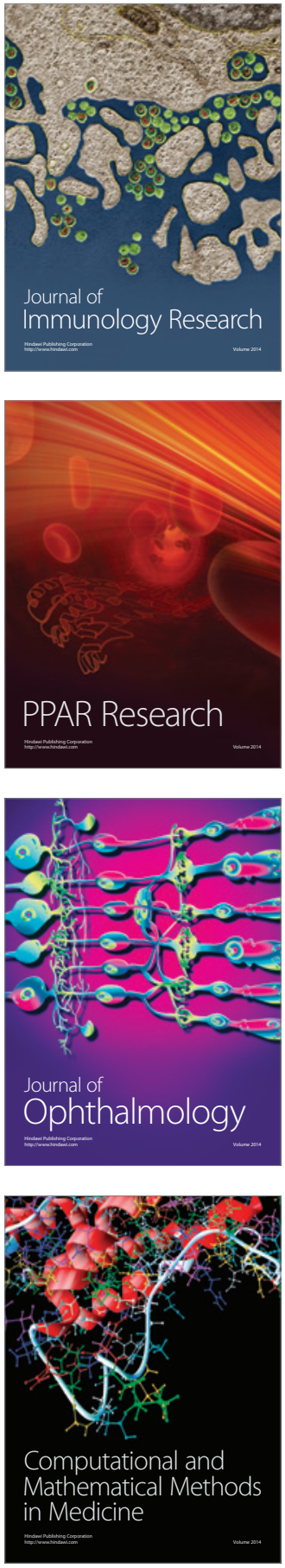

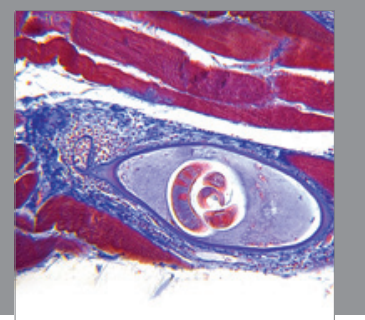

Gastroenterology

Research and Practice
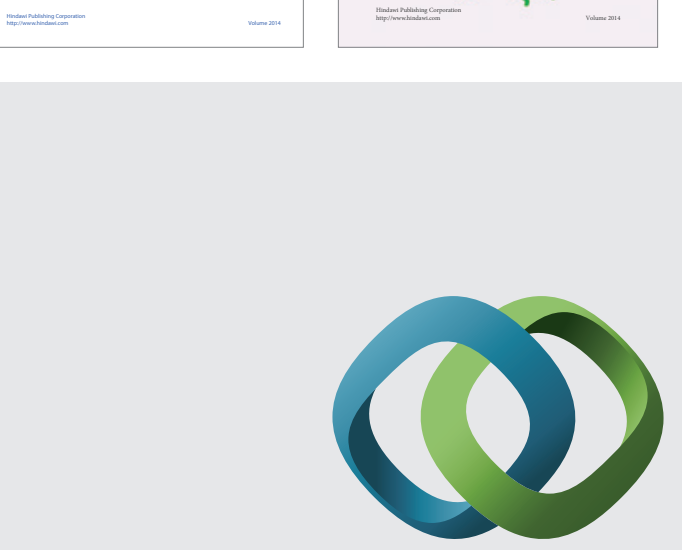

\section{Hindawi}

Submit your manuscripts at

http://www.hindawi.com
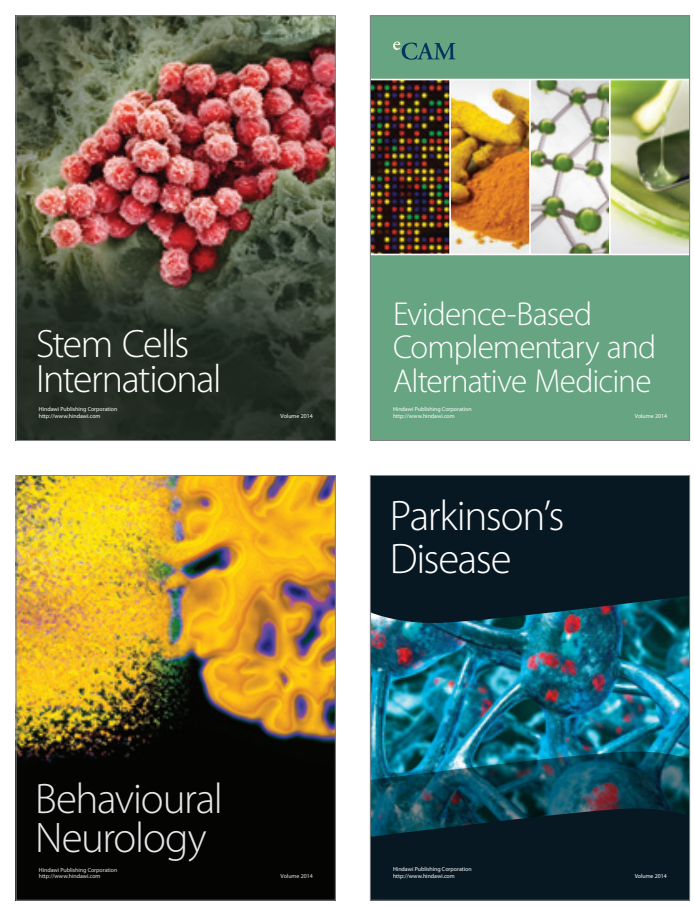

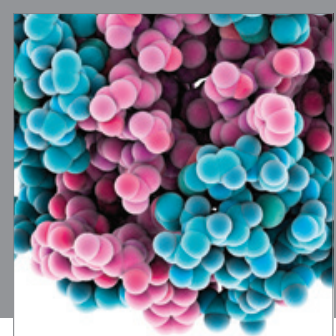

Journal of
Diabetes Research

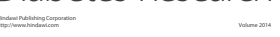

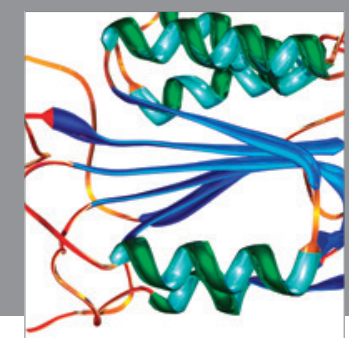

Disease Markers
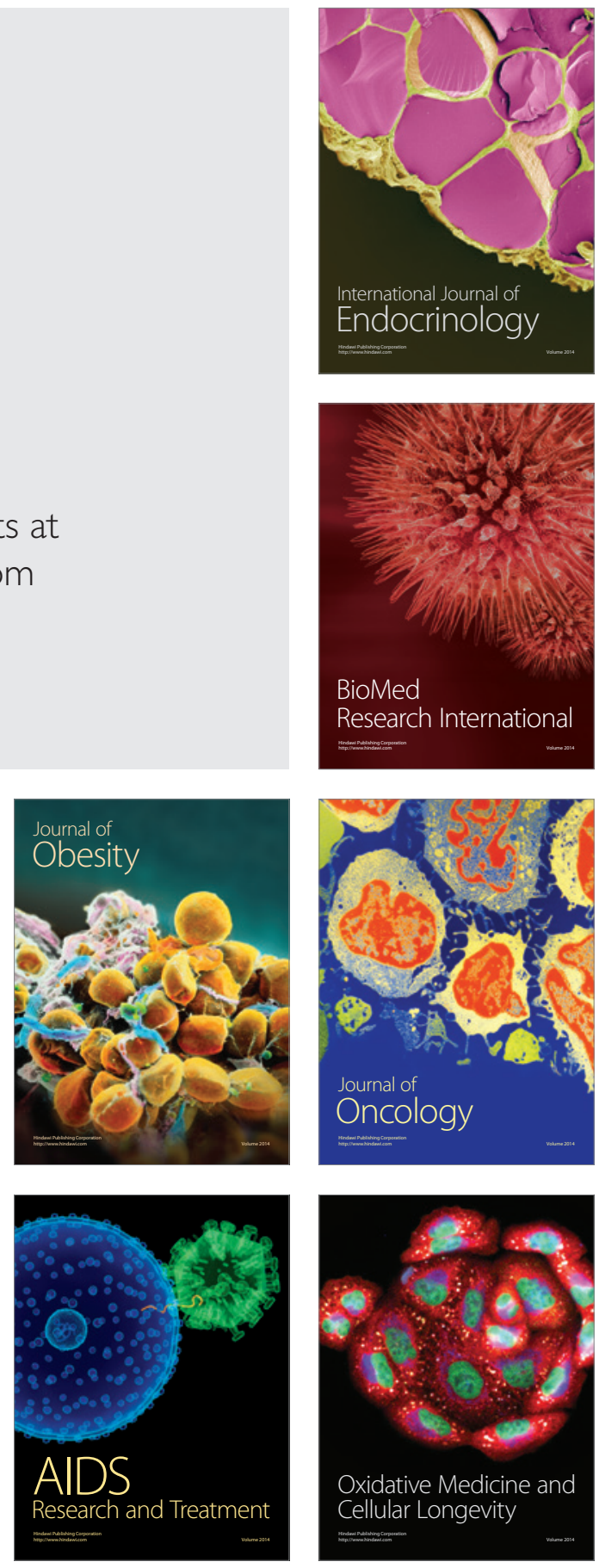